\title{
Moisture Content, Thickness, and Lesions of Sole Horn Associated with Thin Soles in Dairy Cattle
}

\author{
S. R. van Amstel, ${ }^{1}$ J. K. Shearer, ${ }^{2}$ and F. L. Palin ${ }^{3}$ \\ ${ }^{1}$ Department of Large Animal Clinical Sciences, \\ University of Tennessee, PO Box 1071, Knoxville 37901-1071 \\ ${ }^{2}$ Department of Large Animal Clinical Sciences, \\ College of Veterinary Medicine, University of Florida, \\ PO Box 100136, Gainesville 32610-0136 \\ ${ }^{3}$ Department of Psychology, Georgia State University, \\ University Plaza, Atlanta 30303-3083
}

(Key words: moisture content, sole thickness, lameness)

\section{INTRODUCTION}

The protective function of the claw capsule is based on adequate sole thickness of approximately $7 \mathrm{~mm}$ in the area of the toe (Toussaint Raven, 1989). Within certain limits, this is sufficient to withstand mechanical and chemical influences from outside, even at varying temperatures (Toussaint Raven, 1989). Sole thickness is a function of the rate of growth vs. the rate of wear, both of which are affected by several factors. Vermunt and Greenough (1995) found rates of horn growth greater in younger cows than in mature cows, and Greenough et al. (1990) reported that high-energy diets increased the rate of sole horn growth. Rates of claw horn growth have also been shown to be seasonal and follow variations in daily photoperiod. The highest growth rates are found in the spring-summer period (Vermunt and Greenough, 1995). Rates of wear have been associated with concrete walking surfaces, poor cow comfort, commingling of animals, poor horn quality, poor stockmanship, and claw horn moisture (van Amstel et al., 2002). Of these, claw horn moisture could be very important as prolonged water contact of the claw horn occurs in many dairy operations because of flush systems to manage manure or water used in sprinkler systems to clean udders or to reduce heat stress. Such use may result in increased levels of claw horn moisture. Immersion of sole horn in solute-free water resulted in water uptake as evidenced by a $4 \%$ increase in mass after $10 \mathrm{~d}$. Maximum weight change occurred within $48 \mathrm{~h}$ (Wagner and Hood, 2002). Increased moisture content of the horn resulted in an increased rate of wear (Vermunt and Greenough, 1995).

The internal environment of claw horn also affects its moisture content (Bertram and Gosline, 1987; Wagner and Hood, 2002). A hydrostatic force exists between the dermis (corium) and epidermis (horn), moving water

Received May 13, 2003

Accepted November 6, 2003

Corresponding author: S. R. van Amstel; e-mail: svanamst@ utk.edu. 
toward the outer horn cells. The plasmalemma of cornified keratinocytes in the outer layers of the epidermis is highly permeable to the passive movement of water and crystalloids, but not to macromolecules such as protein (Wagner and Hood, 2002). This movement of water creates a gradient in which the outer surface of the horn has a low hydration level while the inner layers adjacent to the dermis maintain a high hydration level (Bertram and Gosline, 1987). In one study, the equine outer hoof wall had an average moisture level of $27.9 \%$ (SD $=1.7 \%)$, and the inner wall samples had a $35.5 \%$ $(\mathrm{SD}=2.5 \%)$ moisture level (Douglas et al., 1996). In addition, a variable osmotic gradient is present inside the cell and is caused by solutes and keratin proteins, which will further regulate the water content of horn cells. Thus, both the internal and external claw environment will determine total sole horn moisture content. Vermunt and Greenough (1995) reported that increased moisture content of horn resulted in an increased rate of wear

An association between toe length and sole thickness has been reported. Toussaint Raven (1989) found that a dorsal wall length of $7.5 \mathrm{~cm}$ was associated with a sole thickness of 5 to $7 \mathrm{~mm}$. In another study, anatomical measurements of adult bovine cadaver claws with a dorsal wall length of $7.5 \mathrm{~cm}$ had an average sole thickness of $8.2 \mathrm{~mm}$ (van Amstel et al., 2002). These findings suggest that adult cows with thin soles may have a toe length of less than $7.5 \mathrm{~cm}(3 \mathrm{in})$.

The lateral claw of the rear leg is commonly more severely affected with thin soles than other claws. Using finger pressure, the sole of this claw becomes flexible, particularly at the toe (Shearer and van Amstel, unpublished observation). Using a pressure distribution plate during standing, maximum pressures were found in the cranial portion of the soles of the lateral claw for rear feet in cows with normal claw conformation (van der Tol et al., 2002).

Contusion of the corium of the sole is an important cause of lameness in confinement conditions and contributes to excessive sole horn wear (Toussaint Raven, 1989). In cases with thin, flexible soles, sole ulcers are associated with vascular injury to the corium, resulting from compression between the flexor tuberosity of the third phalanx and the sole when animals walk on irregular surfaces (Greenough, 1987).

Based on these findings, the following hypotheses were formulated. 1) The sole horn of cows with thin soles have a higher moisture content than those with normal soles. 2) Sole horn thickness within thin-soled cows differs between lateral and medial claws of the rear leg. 3) A dorsal wall length of less than $7.5 \mathrm{~cm}$ is associated with thin soles, defined as being less than 5 mm thick. 4) Lameness associated with thin soles results from the presence of specific claw horn lesions.

Objectives of this investigation included the following: 1) evaluation of the association between moisture content of the sole horn in cows with thin or normal sole thickness in a free-stall environment and 2) characterization the physical and pathological changes, including dorsal wall length, sole thickness, and horn lesions, associated with thin soles in dairy cattle.

\section{MATERIALS AND METHODS}

Measurements were performed on 16 normal and 26 adult Holstein cows with thin soles. The animals were kept in a large, total confinement commercial dairy operation in 4 free-stall barns bedded with sand. Concrete walkways between the free stalls and feed bunks situated in the center of the barn were scraped twice daily. Cows were milked twice daily. Before each milking, udders were cleaned using water sprayers in the holding area. The floor of the parlor was frequently flushed. The return alley is used for drainage of flush water; thus, cows' feet were exposed to high levels of moisture on return to the free stalls. All walking surfaces were longitudinally grooved concrete. Selection criteria for prospective thin-soled cows included a short dorsal wall (toe length) of $7.5 \mathrm{~cm}$ or less and some or all of the following clinical signs: painful gait, arched back, or specific leg lameness. Sixteen nonlame adult cows with dorsal wall length in excess of $7.5 \mathrm{~cm}$ were randomly selected. Both groups of cows were exposed to the same amount of moisture, walking surface, and distance to the milking parlor. None of the cows in the study had undergone recent trimming.

Cows in both groups were restrained on a tilt table for claw evaluations. These evaluations included collections of sole samples from all cows in both groups for determination of moisture content as well as ultrasound measurement of sole thickness of the rear claws of cows in the thin-soled group. The claws, including the wall, sole, and interdigital space, were cleaned with water and a brush and then dried. Using a hoof knife, sole horn samples were collected adjacent to the interdigital space from both front and rear feet (zone 4; Figures 1 and 2). The knife was held at an angle to avoid the axial wall and to remove sole horn only. Using visual judgment, the angle and depth of the cut was approximately the same for all claws in both groups during the sampling procedure. Samples differed in size depending on the amount of available sole. The surface of the samples was dried using absorbent towels and weighed on an electronic scale (Fisher Scientific model S - 300D; Brinkman Instruments, Westbury, NY) and weight recorded in grams. Samples were identified, placed in 


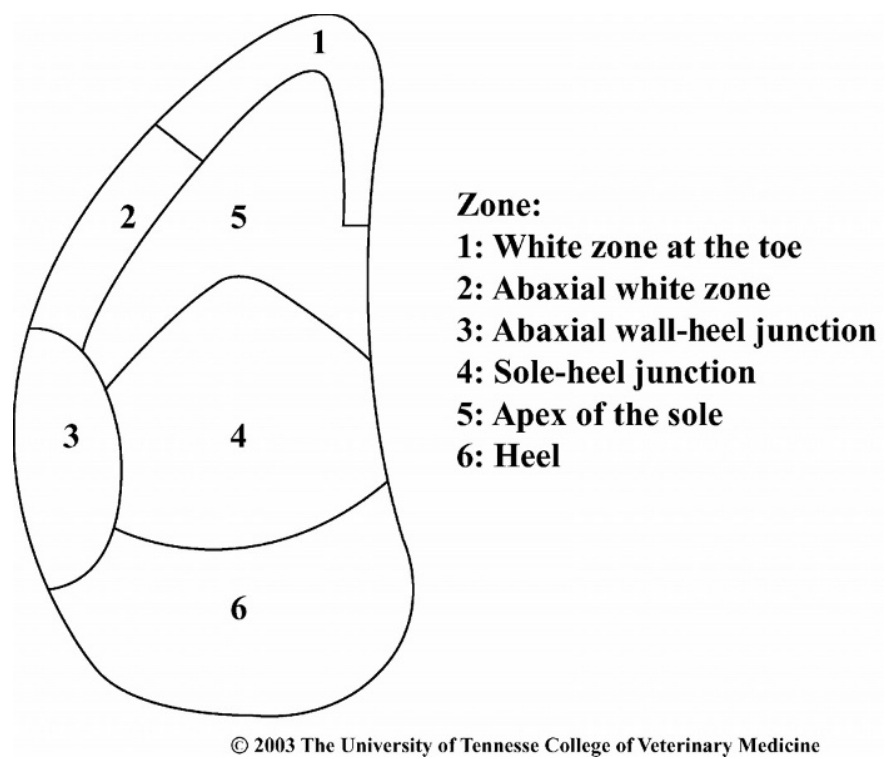

Figure 1. Description of claw zones used in evaluation of claw disorders and sole thickness in dairy cows.

airtight plastic bags, kept on ice, placed in a drying oven within $48 \mathrm{~h}$, and dried at $43.5^{\circ} \mathrm{C}$ for $50 \mathrm{~h}$. Samples were reweighed, and the water content calculated was based on weight loss (Hinterhofer et al., 1998).

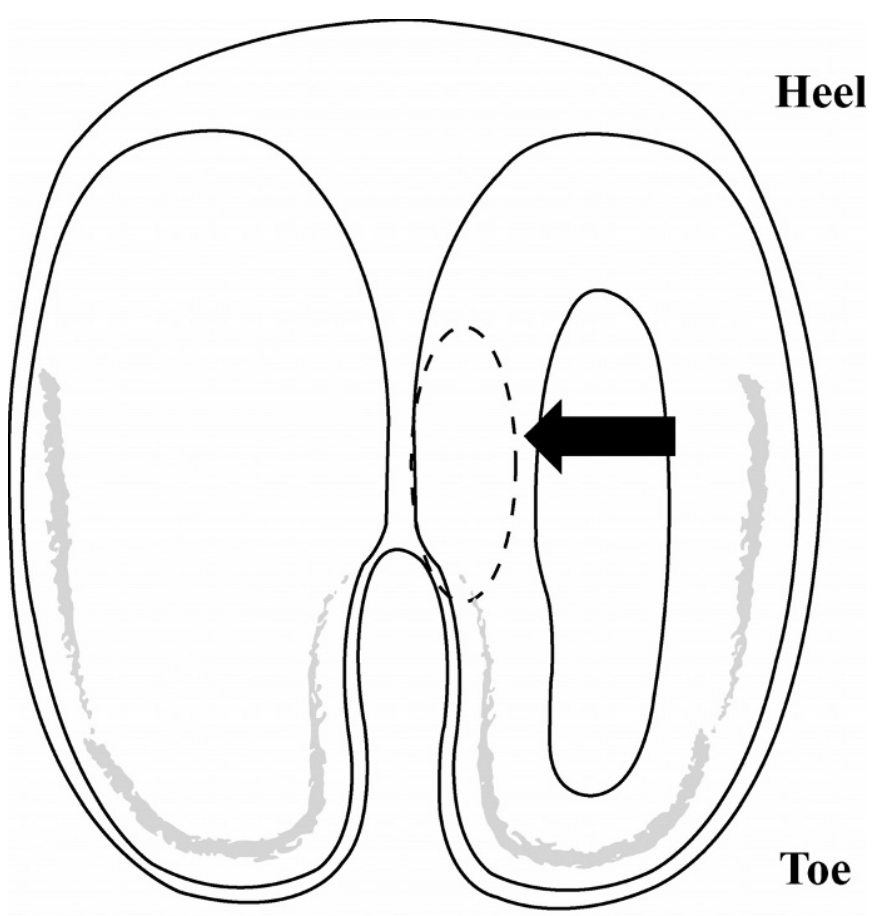

(C) 2003 The University of Tennesse College of Veterinary Medicine

Figure 2. Schematic identifying sample collection site on sole region of dairy cattle claws.

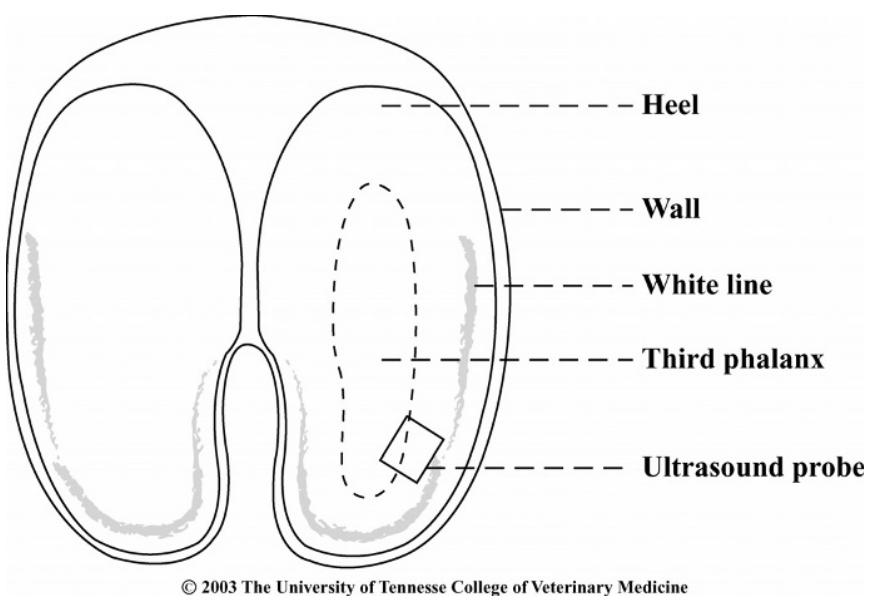

Figure 3. Schematic illustration of placement of the ultrasound probe approximately $3.75 \mathrm{~cm}$ behind the apex of the toe and on the inside of the abaxial white line (transition of zones 1 and 2).

Ultrasound measurement (B mode) of sole thickness for rear claws was carried out with cows restrained on the tilt table using a Toshiba "JustVision 200" machine (model SSA-320A; Toshiba Corp., Otawara-shi, Tochigiken 324, Japan) and a 7.0-MHz curvilinear transducer with a measurement accuracy of $0.1 \mathrm{~mm}$. After spraying sole surfaces of the rear claws with alcohol and applying transmission gel to the transducer's contact surface, ultrasound measurement was carried out approximately $3.75 \mathrm{~cm}$ behind the apex of the toe and on the inside of the abaxial white line (transition of zones 1 and 2; Figures 1 and 3). Sole thickness represents the area between the outer margin of the ultrasound image and the inner sole/soft tissue margin seen as a thin continuous or interrupted hyperechoic line (Figure 4) (Kofler et al., 1999). The point of reference for measurement of sole thickness was the abaxial ventral margin of the third phalanx, at the start of the contour visible on its ventral surface (Figure 4). To limit the time cows were restrained on the tilt table, sole thickness was recorded for all 4 claws of the rear but not the front legs, because the researchers had previously observed that rear feet are more commonly affected with thin soles than are front feet (van Amstel and Shearer, unpublished observation). Ultrasound measurements of sole horn thickness were successfully determined in all 4 rear claws in 15 of the 26 cattle with thin soles.

Using a ruler marked in inches, measurement of the dorsal wall (toe) length was carried out along the ridge made by the junction of the abaxial and axial walls, from just below the coronet to the bearing surface at the toe. 


\section{Ventral}

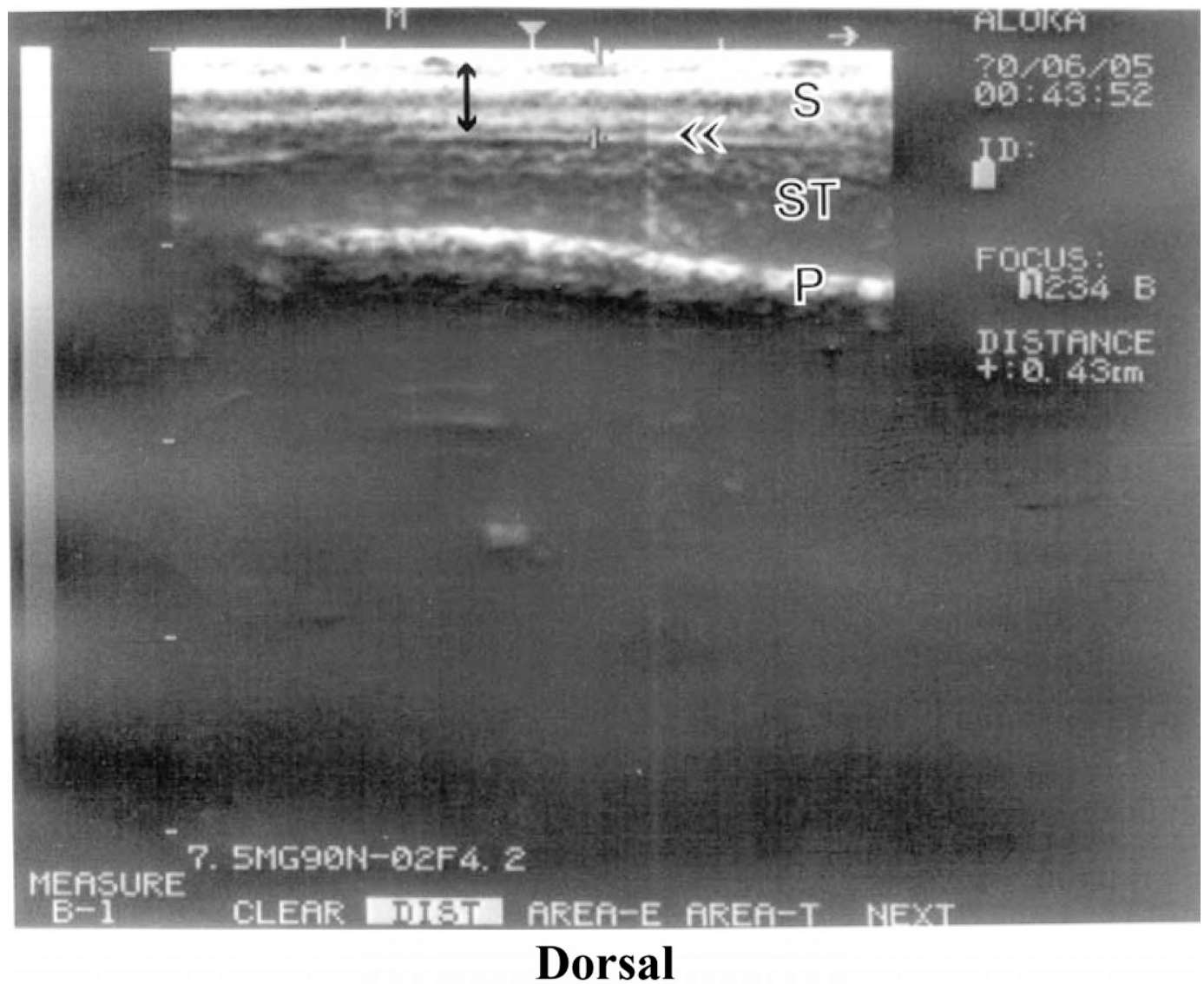

(C) 2003 The University of Tennesse College of Veterinary Medicine

Figure 4. Longitudinal ultrasound image of the abaxial margin of the claw in the toe region of the sole (zone 5) directly adjacent to the white line (zone 1). The sole horn (S), soft tissue (ST), ventral surface of the third phalanx (P), and inner margin of the sole (double arrow heads) can be seen. Thickness of the sole horn was measured from the bearing surface to the inner margin of the sole (arrow).

\section{Statistical Analyses}

The effects of sole thickness (normal vs. thin soles) and location (front vs. rear claws) on moisture content levels in claws of Holstein cattle were evaluated using a $2 \times 2$ ANOVA with covariates. Data from the front and rear claws of 16 cattle with normal soles and of 26 cattle with thin soles were used for the statistical analyses. Descriptive statistics (means, standard deviations, standard errors, and confidence intervals) were calculated for both independent variables. The cattle in the study were highly homogenous in terms of breed (Holstein), diet (total mixed ration), environment (dairy), and health status (healthy). Because of some variability in age and days in milk, both variables were included as covariates. A between-subjects design was chosen, as opposed to a within-subjects design, because of the homogeneity of the cattle in the study and the conceptualization of the front and rear claws of each cow as independent entities, i.e., left and right (front and rear legs) were considered independent entities.

Differences in sole thickness based on location (medial vs. lateral claws) of 15 of the 26 cattle with thin soles, those for which ultrasound measurements of sole horn thickness were successfully determined in all four rear claws, were assessed using a one-way ANOVA with age and days in milk as covariates. Descriptive statistics of sole thickness based on location were calculated. All results in this study were considered significant at $P<0.05$. Statistical software was used for all of the analyses (version 10.0; SPSS Inc., Chicago, IL).

\section{RESULTS}

Refer to Table 1 for a summary of the descriptive statistics for the 2 groups. The ANOVA indicated no significant covariate effects for age $[F(1,78)=3.34$; $\mathrm{P}=0.07]$ or days in milk $[F(1,78)=0.07 ; P=0.79]$. 
Table 1. Sole moisture content levels in front and rear claws of dairy cows with thin and normal sole thickness.

\begin{tabular}{llllllll}
\hline & & & & & & \multicolumn{2}{c}{$95 \%$ Confidence Interval $^{1}$} \\
\cline { 6 - 7 } $\begin{array}{l}\text { Foot } \\
\text { location }\end{array}$ & $\begin{array}{l}\text { Sole } \\
\text { thickness }\end{array}$ & $\mathrm{N}$ & $\begin{array}{l}\text { Mean } \\
\text { \% moisture }\end{array}$ & $\mathrm{SD}$ & $\mathrm{SE}^{\mathrm{a}}$ & $\begin{array}{l}\text { Lower } \\
\text { bound }\end{array}$ & $\begin{array}{l}\text { Upper } \\
\text { bound }\end{array}$ \\
\hline Front & Thin & 26 & $37.13^{\mathrm{a}}$ & 4.71 & 0.73 & 35.69 & 38.58 \\
& Normal & 16 & $31.08^{\mathrm{b}}$ & 3.39 & 0.93 & 29.22 & 32.93 \\
Rear & Thin & 26 & $40.46^{\mathrm{a}}$ & 3.33 & 0.73 & 39.02 & 41.91 \\
& Normal & 16 & $33.14^{\mathrm{b}}$ & 2.44 & 0.93 & 31.29 & 35.00 \\
Front & - & 42 & $34.10^{\mathrm{c}}$ & 5.08 & 0.58 & 38.47 & 35.26 \\
Rear & - & 42 & $36.80^{\mathrm{d}}$ & 4.57 & 0.58 & 35.64 & 37.96 \\
- & Thin & 52 & $38.80^{\mathrm{a}}$ & 4.37 & 0.52 & 37.76 & 39.83 \\
- & Normal & 32 & $32.11^{\mathrm{b}}$ & 3.09 & 0.67 & 30.78 & 33.44 \\
\hline
\end{tabular}

${ }^{1}$ Evaluated at covariates (age and lactation).

a,b Significant difference in moisture based on thickness $(P=0.001)$.

${ }^{\mathrm{c}, \mathrm{d}}$ Significant difference in moisture based on location $(P=0.002)$.

Moreover, a significant interaction between sole thickness and location was not detected $[F(1,78)=0.59 ; P=$ 0.45]. Significant main effects for both sole thickness $[F$ $(1,78)=59.40 ; P=0.001 ;$ partial $\left.\eta^{2}=0.43\right]$ and location $\left[F(1,78)=10.72 ; P=0.002 ;\right.$ partial $\left.\eta^{2}=0.12\right]$ were found. These results suggest that 1 ) thin soles had higher moisture content levels than normal soles; 2) rear claws had higher moisture content levels than front claws; 3) thin soles had higher moisture content levels than normal soles, regardless of location; and 4) rear claws had higher moisture content levels than front claws, regardless of sole thickness. The rank ordering of moisture content levels in ascending order as a function of sole thickness and location was 1) normal, front; 2) normal, rear; 3) thin, front; and 4) thin, rear. Thus, rear claws of thin-soled cattle tended to have the highest moisture content levels. Sole thickness was more highly related to moisture content levels (partial $\eta^{2}=0.43$ ) than was location (partial $\eta^{2}=0.12$ ). Both sole thickness and location were important variables in this model, accounting for $46 \%$ of the variance of moisture content levels (model adjusted $\eta^{2}=0.46$ ). In other words, this effect of size indicates not only a statistically significant relationship between sole thickness and location and moisture content levels, but also shows a clinical significant effect (Altman and Bland, 1995).

Refer to Table 2 for a summary of the descriptive statistics for medial vs. lateral claws within thin-soled cows. The ANOVA indicated no significant covariate effects for age $[F(1,56)=1.50 ; P=0.23]$ or days in milk $[F(1,56)=0.14 ; P=0.72]$. The effect for location was significant $[F(1,56)=12.78 ; P=0.001]$, indicating that the medial claws of thin-soled cattle were significantly thicker than their lateral claws. The average dorsal wall (toe) lengths were $66.8 \pm 3.9 \mathrm{~mm}$ for rear lateral claws and $69.1 \pm 7.2 \mathrm{~mm}$ for rear medial claws.

Thirty percent of rear feet of lame cows had pathological claw horn lesions; sole/white line separation (72\%) was the most common. White line lesions occurred most commonly at the junction of zones 1,2 , and 5 (Figure 1 ) and to a lesser extent at zone 3 . The lesion at zones 1 and 2 did not primarily involve the horn of the white line, but rather presented as a break or separation between the remaining layer of thin sole and white line. Sole ulcers represented $28 \%$ of sole horn lesions and occurred most commonly at the interdigital area of zone 4. Of the affected claws, $13 \%$ had more than one lesion. Seventy-seven percent of claw lesions occurred in the lateral claw

\section{DISCUSSION}

Sole horn moisture of normal cows in this study $(\overline{\mathrm{x}}=$ $32.1 \%$ ) is similar to sole horn moisture levels of $30.4 \%$ reported for cows by Thysen (1987). Cows in that study were also kept in cubicles with solid flooring. Cows kept on slatted flooring had $28.8 \%$ sole horn moisture, and animals kept in tie stalls had a lower mean moisture content for sole horn, 21.5\% (Thysen, 1987). The housing system, therefore, seems to play an important role in the level of moisture in sole horn.

In this study, moisture content of sole horn for both thin-soled and normal cows for rear claws was significantly higher than that for front claws. Vermunt and Greenough (1995) also reported higher moisture levels in rear as compared with front claws. There could be several reasons for this difference in moisture content. The front claws are larger and have thicker soles compared with rear claws (Vermunt and Greenough, 1995; Phillips et al., 1996), which could result in lower moisture levels in the outer sole horn layers (Bertram and Gosline, 1987). Another reason could be related to poor cow comfort in cubicle housing, where cows are commonly observed to stand with their front legs on the bedding and their rear legs in the alleyway, where they 
Table 2. Sole thickness measurements on medial and lateral rear claws of thin-soled dairy cows housed in free stalls.

\begin{tabular}{|c|c|c|c|c|c|c|c|c|}
\hline \multirow[b]{3}{*}{ Location } & \multirow[b]{3}{*}{$\mathrm{N}$} & \multirow[b]{3}{*}{ Mean $^{1}$} & \multirow[b]{3}{*}{ SD } & \multirow[b]{3}{*}{$\mathrm{SE}^{\mathrm{a}}$} & \multicolumn{2}{|c|}{$95 \%$ Confidence Interval $^{\mathrm{a}}$} & \multirow{2}{*}{\multicolumn{2}{|c|}{ Range }} \\
\hline & & & & & Lower & Un & & \\
\hline & & & & & bound & bound & Min. & Max. \\
\hline Medial & 30 & $5.15^{\mathrm{a}}$ & 0.98 & 0.18 & 4.79 & 5.52 & 3.00 & 7.90 \\
\hline Lateral & 30 & $4.23^{\mathrm{b}}$ & 1.01 & 0.18 & 3.87 & 4.60 & 2.40 & 7.20 \\
\hline
\end{tabular}

${ }^{1}$ Evaluated at covariates (age and lactation).

${ }^{\text {a,b }}$ Statistically different at $P=0.001$.

are constantly exposed to moisture from manure and urine.

Immersion of horn in solute-free water for $10 \mathrm{~d}$ resulted in maximum uptake after $48 \mathrm{~h}$ (Wagner and Hood, 2002). Therefore, increased softness and flexibility of sole horn should occur within a short period after introduction of cows into a moisture-rich environment. In this study, sole horn of thin-soled cows had significantly more moisture than those of normal-soled cows. The reason for this may be due to the presence of less mature keratinocytes on the bearing surface, which have higher moisture content (Bertram and Gosline, 1987; Douglas et al., 1996), in addition to absorbed environmental moisture. Horn quality and structure may also affect moisture content. Thysen (1987) reported higher moisture levels in laminitic horn than in normal horn. None of the cows in either of the 2 groups in this study showed obvious signs of laminitis.

Whether thin-soled cows have more moisture because they are thin-soled or whether some cattle absorb more moisture than others remains a question. The thin sole problem may be self-perpetuating because an increase in sole horn moisture may result in an increased rate of wear because of softer horn. The increase in flexibility associated with increased moisture levels may somewhat counter increases in rates of wear (Vermunt and Greenough, 1995).

This study found no significant covariate effects for age $(P=0.07)$ or days in milk $(P=0.79)$, although results suggest that there may be a trend toward a higher prevalence of thin soles in younger cattle. This result corresponds with unpublished reports from several large dairies and needs further investigation. Other factors that may result in thin soles include concrete walking surfaces, poor cow comfort, commingling of animals, poor horn quality, poor stockmanship, and trimming (van Amstel et al., 2002). In this study, all cows in both groups were subject to the same environment and had not recently been subject to claw trimming.

Sole thickness of the lateral claw of thin-soled cows was significantly less than that of the medial claw. The biomechanics of weight bearing leads to unequal distribution of weight between claws of the rear leg; the lateral claw carries more weight than the medial claw (Toussaint Raven, 1989). Using a pressure plate, van der Tol et al. (2002) found maximum pressures in the lateral rear claws during standing. This unequal weight bearing may lead to disproportionate wear on hard and abrasive surfaces, and the lateral claw perhaps wears at a faster rate. Another study found that when soles of both rear claws belonging to the same foot were trimmed to the same level to create a flat bearing surface across both claws and at right angles with a vertical line between the claws, the sole thickness of the lateral claw was significantly less than that of the medial claw (Paulus and Nuss, 2002). This result could suggest that the corium and subcutaneous tissue of the lateral claw is thicker or that perhaps the lateral digit is longer. In situations in which there is accelerated wear of horn, such as with abrasive walking surfaces, hypertrophy of the subsolar soft tissues may account to some extent for the observation that the lateral claw of the rear leg is more commonly affected by thin soles (Shearer and van Amstel, unpublished observation).

\section{CONCLUSIONS}

Cows with thin-soled claws have higher levels of moisture than cows with normal sole thickness from the same herd. Highest claw moisture levels were recorded in the rear feet.

\section{REFERENCES}

Altman, D. G., and J. M. Bland. 1995. Absence of evidence is not evidence of absence. Br. Med. J. 311:485.A

Bertram, J. E. A., and J. M. Gosline. 1987. Functional design of horse hoof keratin: The modulation of mechanical properties through hydration effects. J. Exp. Biol. 130:121-136.

Douglas, J. E., C. Mittal, J. J. Thomason, and J. C. Jofriet. 1996. The modulus of elasticity of equine hoof wall: implications for the mechanical function of the hoof. J. Exp. Biol. 199:1829-1836.

Greenough, P. R. 1987. Pododermatits Circumscripta (ulceration of the sole) in cattle. Agri-Pract. (Nov/Dec):17-22.

Greenough, P. R., J. J. Vermunt, J. J. McKinnon, J. J. Fathy, F. A. Berg, P. A. Cohen, and R. D. H. Cohen. 1990. Laminitis-like changes in the claws of feedlot cattle. Can. Vet. J. 31:202-208. 
Hinterhofer, C., C. Stanek, and K. Binder. 1998. Elastic modulus of equine hoof horn, tested in wall samples, sole samples and frog samples at varying levels of moisture. Berl. Munch. Tierarz. Wschr. 11:217-221.

Kofler, J., P. Kubber, and W. Henninger. 1999. Ultrasonographic imaging and thickness measurement of the sole horn and underlying soft tissue layer in bovine claws. Vet. J. 157:322-331.

Paulus, N., and K. Nuss. 2002. Claw measurements at defined sole thickness. Pages 428-430 in Proc 12th Int. Symp. on Lameness in Ruminants, Orlando, FL.

Phillips, C. J. C., S. J. Patterson, I. A. Dewi, and C. J. Whitaker. 1996. Volume assessment of the bovine hoof. Res. Vet. Sci. 6:125-128.

Thysen, I. 1987. Foot and leg disorders in dairy cattle in different housing systems. Pages 166-178 in Cattle Housing Systems, Lameness and Behavior. H. K. Wierenga and D. J. Peterse, ed. Martinus Nijhoff Publishers, Boston, MA.
Toussaint Raven, E. 1989. Structure and Function. Pages 24-26 in Cattle Foot Care and Claw Trimming. E. Toussaint Raven, ed. Farming Press, Ipswitch, UK.

van Amstel, S. R., F. L. Palin, J. K. Shearer, and B. F. Robinson. 2002. Anatomical measurement of sole thickness in cattle following application of two different trimming techniques. Bovine Pract. 36:136-140.

van der Tol, P. P. J., J. H. M. Metz., E. N. Noordhuizen-Stassen., W. Back, C. R. Braam, and W. A. Weijs. 2002. The pressure distribution under the bovine claw during square standing on a flat substrate. J. Dairy Sci. 85:1476-1481.

Vermunt, J. J., and P. R. Greenough. 1995. Structural characteristics of the bovine claw: Horn growth and wear, horn hardness and claw conformation. Br. Vet. J. 151:157-180.

Wagner, I. P., and D. M. Hood. 2002. Effect of prolonged water immersion on equine hoof epidermis in vitro. Am. J. Vet. Res. 63:1140-1144. 